\title{
A case of eczema herpeticum with Hailey-Hailey disease: A potential diagnostic pitfall
}

\section{Anissa Zaouak, Leila Bouhajja, Houda Hammami, Samy Fenniche}

\author{
Department of Dermatology, Habib Thameur Hospital, Tunis, Tunisia
}

Corresponding author: Dr. Anissa Zaouak, E-mail: anissa_zaouak@yahoo.fr

Sir,

We report the case of a 48 -year-old female with a medical history of Hailey-Hailey disease. The patient had been followed since the age of 30 years for Hailey-Hailey disease, which had affected the axillary and inguinal region (Fig. la). The presence of intraepidermal clefts in the epidermis with dyskeratotic cells and acantholysis with the characteristic appearance of a dilapidated brick wall was confirmed histologically (Fig. lb). The patient was treated with topical corticosteroids and dapsone $100 \mathrm{mg} /$ day. She was referred for painful lesions and a burning sensation in the groin present for the last two days. A physical examination revealed multiple vesiculopustules on erythematous plaques with linear ulcerations in the inguinal region (Fig. 2). She had no fever and no lesions elsewhere. A skin biopsy revealed Hailey-Hailey disease with herpetic eczema. The patient was treated with acyclovir $500 \mathrm{mg}$ three times a day administered intravenously for ten days with a favorable outcome.

Hailey-Hailey disease is a rare genodermatosis with autosomal dominant inheritance and incomplete penetrance [1]. Clinically, it presents itself as flaccid vesicles and fissures in intertriginous areas [2] with superficial linear erosions with crusts and maceration. Heat, sweating, and friction often exacerbate the disease. In addition to the classic bacterial and fungal infections, which may complicate the course of Hailey-Hailey disease, a herpes simplex infection may worsen Hailey-Hailey lesions [2]. Herein, we report a case of Hailey-Hailey disease with coexistent herpes virus infection located in the inguinal region. Hailey-Hailey disease with coexistent HSV (herpes simplex virus) infection is rarely reported in the literature. In fact, HaileyHailey disease is a primary acantholytic disease which could be complicated by a secondary acantholytic disorder, such as a herpes virus infection [3]. The diagnosis should be suspected clinically when lesions of the inguinal region become painful with acute flaring of multiple vesiculopustules associated with painful erosions. The diagnosis suspected clinically should be confirmed by viral culture, PCR, and a skin biopsy. Skin cytology, as reported by de Aquino Paulo Filho [2], is a rapid diagnostic tool showing giant viral multinucleated cells that could guide the early diagnosis of an HSV infection. The risk factors include rupture of the epidermal barrier and the use of corticosteroids [1-5]. Indeed, the disruption of the stratum corneum and the fragility of the epidermis in Hailey-Hailey disease make it easy for HSV to infect and proliferate [6]. Rapid diagnosis of this complication is advised for quick treatment and to avoid systemic complications. In fact, it is a potentially life-threatening viral infection that may be disseminated, leading to visceral involvement and death [4]. Therapy should be initiated without delay if there is a high suspicion or a positive Tzanck smear with high-dose intravenous antiviral drugs such as acyclovir [2]. Timely recognition of this complication helps to improve the prognosis of the disease [4].

In summary, this case is being reported to increase awareness of the rare association between HaileyHailey disease and HSV infection, which may be severe and which frequently alters the quality of life of affected patients.

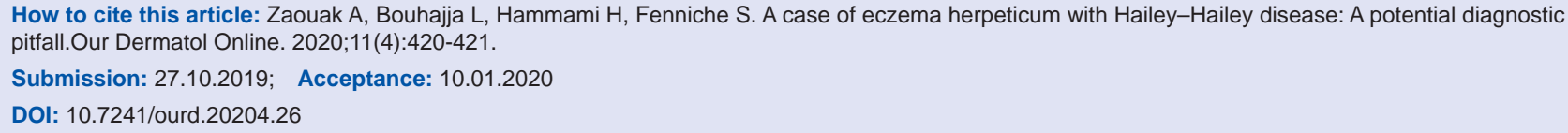




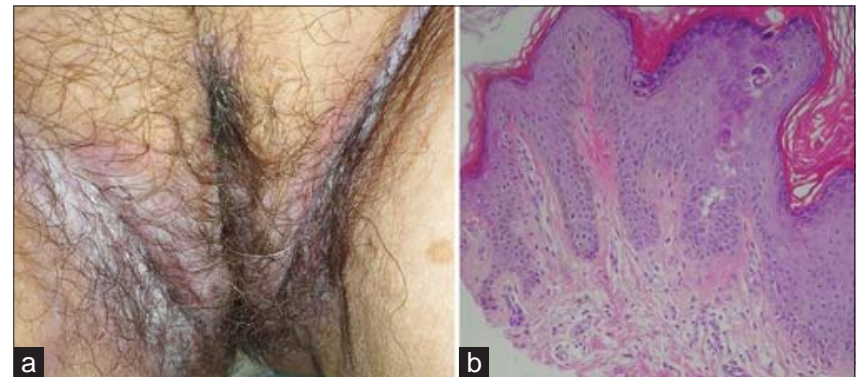

Figure 1: (a) White plaques in the inguinal region with linear fissures. (b) Intraepidermal clefts in the epidermis with dyskeratotic cells and acantholysis with the characteristic appearance of a dilapidated brick wall $(\mathrm{H} \& \mathrm{E}, 100 \times)$.

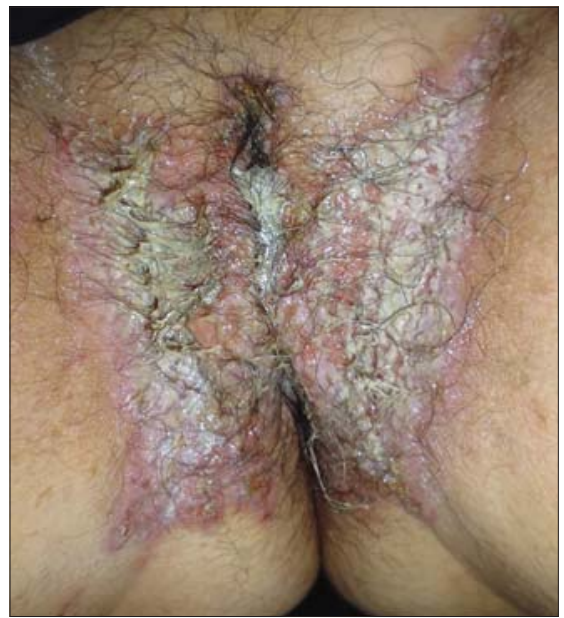

Figure 2: Multiple vesiculopustules with small erosions on an erythematous base in the inguinal region.

\section{Consent}

The examination of the patient was conducted according to the principles of the Declaration of Helsinki.
The authors certify that they have obtained all appropriate patient consent forms, in which the patients gave their consent for images and other clinical information to be included in the journal. The patients understand that their names and initials will not be published and due effort will be made to conceal their identity, but that anonymity cannot be guaranteed.

\section{REFERENCES}

1. Al Hamzawi NK. Hailey-Hailey disease presenting at unusual site. Our Dermatol Online. 2019;10:108-9.

2. de Aquino Paulo Filho T, de Freitas YK, da Nóbrega MT, Lima CB, Carriço BL, Silva MA, et al. Hailey-Hailey disease associated with herpetic eczema-the value of the Tzanck smear test. Dermatol Pract Concept. 2014;4:29-31.

3. Leitch CS, Panthagani AP, Tidman MJ, Biswas A. Hailey-Hailey disease with coexistent herpes virus infection: insights into the diagnostic conundrum of herpetic/pseudoherpetic features in cutaneous acantholytic disorders. Am J Dermatopathol. 2018;40:749-53.

4. Tomaszewska K, Oszukowska M, Zalewska-Janowska A, Kaszuba A. Linear IgA bullous disease presenting as a Hailey-Hailey disease associated with Hashimoto thyroiditis: a case report. Our Dermatol Online. 2019;10:284-5.

5. Chourabi M, H'mida-Ben Brahim D, Bonnard C, Aounallah A, Yu $\mathrm{Ng} \mathrm{A}$, Tohari S, et al. A novel nonsense ATP2C1 mutation causes Hailey-Hailey disease in a Tunisian family. Our Dermatol Online. 2018;9:110-3

6. Brzeziński P, Martini L. Frazier-Yeager's Eczema herpeticum in a lycanthrope: The way to prepare natural antibiotics at home to defeat the topical blemishes and imperfections of many areas of the affected body. Our Dermatol Online. 2020;11:e4.1-e4.2.

Copyright by Anissa Zaouak, et al. This is an open-access article distributed under the terms of the Creative Commons Attribution License which permits unrestricted use, distribution, and reproduction in any medium, provided the original author and source are credited.

Source of Support: Nil, Conflict of Interest: None declared. 